\title{
Editorial
}

\section{Nuclear Fusion}

\section{Mahmood Ghoranneviss, ${ }^{1}$ S. K. S. Parashar, ${ }^{2}$ Necdet Aslan, ${ }^{3}$ Morteza Aslaninejad, ${ }^{4}$ and A. Salar Elahi ${ }^{1}$}

\author{
${ }^{1}$ Plasma Physics Research Center, Islamic Azad University, Science and Research Branch, Tehran, Iran \\ ${ }^{2}$ School of Applied Sciences, KIIT University, Bhubaneswar, India \\ ${ }^{3}$ Physics Department, Yeditepe University, Istanbul, Turkey \\ ${ }^{4}$ Department of Physics, Imperial College London, London, UK
}

Correspondence should be addressed to A. Salar Elahi; Salari_phy@yahoo.com

Received 4 May 2014; Accepted 4 May 2014; Published 26 May 2014

Copyright (c) 2014 Mahmood Ghoranneviss et al. This is an open access article distributed under the Creative Commons Attribution License, which permits unrestricted use, distribution, and reproduction in any medium, provided the original work is properly cited.

This special issue is the first one published in this journal. This special issue covered engineering and scientific advances in both inertial and magnetic confinement fusion, with attendees from major fusion energy research centers worldwide. It is one of the most important issues in this field. Nuclear fusion continues to be an important area, given the continued engineering and technology advances in magnetic and inertial thermonuclear fusion. The objective of this special issue is to bring the most up-to-date developments in nuclear fusion to the readership of this journal. This special issue highlights works in the area of nuclear fusion engineering, including ITER and experimental fusion devices, which include alternate fusion confinement devices; new device design and reactor studies; divertors and plasmamaterial interactions; chambers; vacuum vessels related to fusion device technology; plasma diagnostics; data acquisition and plasma control systems; safety and environmental engineering; plasma fueling; pumping and tritium handling systems; inertial fusion energy drivers; targets and related technologies; fusion device power systems; magnet engineering; electromagnetics; and electromechanics. This special issue highlights a wide diversity of topics in nuclear fusion engineering. We are thrilled by the diversity and the high quality of the papers submitted to and published in this special issue. The ITER Project continues to move ahead. Construction at the Cadarache site is quite remarkable. Buildings completed include the huge Poloidal Field Coils
Winding Facility and the Headquarters building, which has been occupied by the ITER Staff. The base of the Tokamak complex is being laid. Besides the construction that is taking place and will take place at the site, components from around the world have to navigate the complex route from Marseilles to the site. Nuclear fusion is proud to continue its key role in providing the leading forum for the documentation of scientific progress and exchange of research results internationally toward fusion energy. In this issue, "Spontaneous emission of an excited atom in a dusty unmagnetized plasma medium" was presented by N. Alinejad and N. Pishbin. "The effect of deposition rate on morphology and structural properties of carbon-nickel composite films" was presented by S. Elahi et al. "Effect of $\mathrm{Ar} / \mathrm{CH} 4$ mixture ratio on properties of $\mathrm{Ag} / \mathrm{C}: \mathrm{H}$ nanocomposite prepared by DC sputtering" was presented by E. M. Soltani et al. Also, "Effect of size distribution on the dust acoustic solitary waves in dusty plasma with two kinds of nonthermal ions" was presented by S. S. Moghadam and D. Dorranian.

Mahmood Ghoranneviss S. K. S. Parashar Necdet Aslan Morteza Aslaninejad A. Salar Elahi 

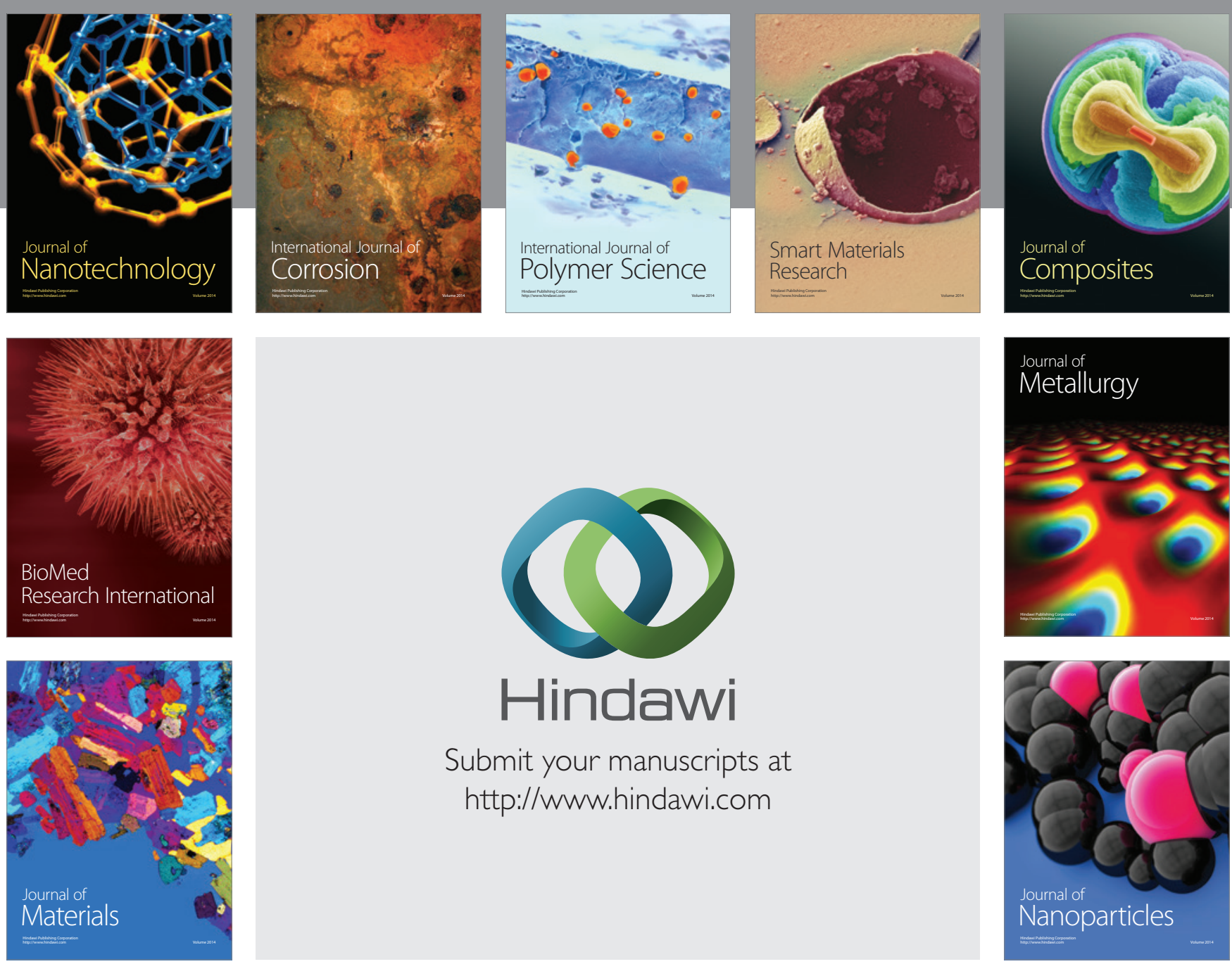

Submit your manuscripts at http://www.hindawi.com
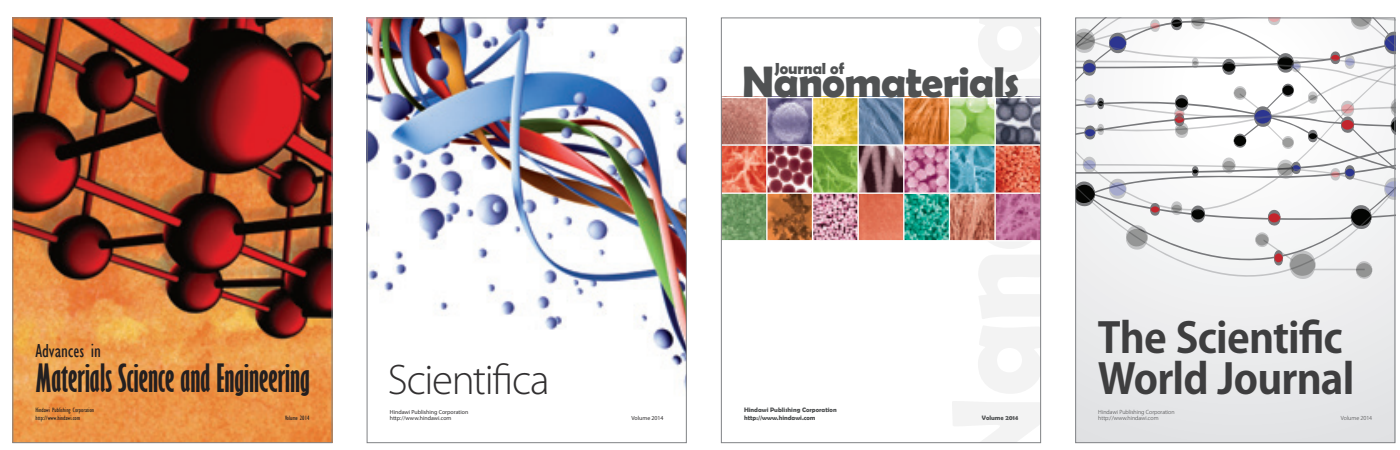

\section{The Scientific World Journal}
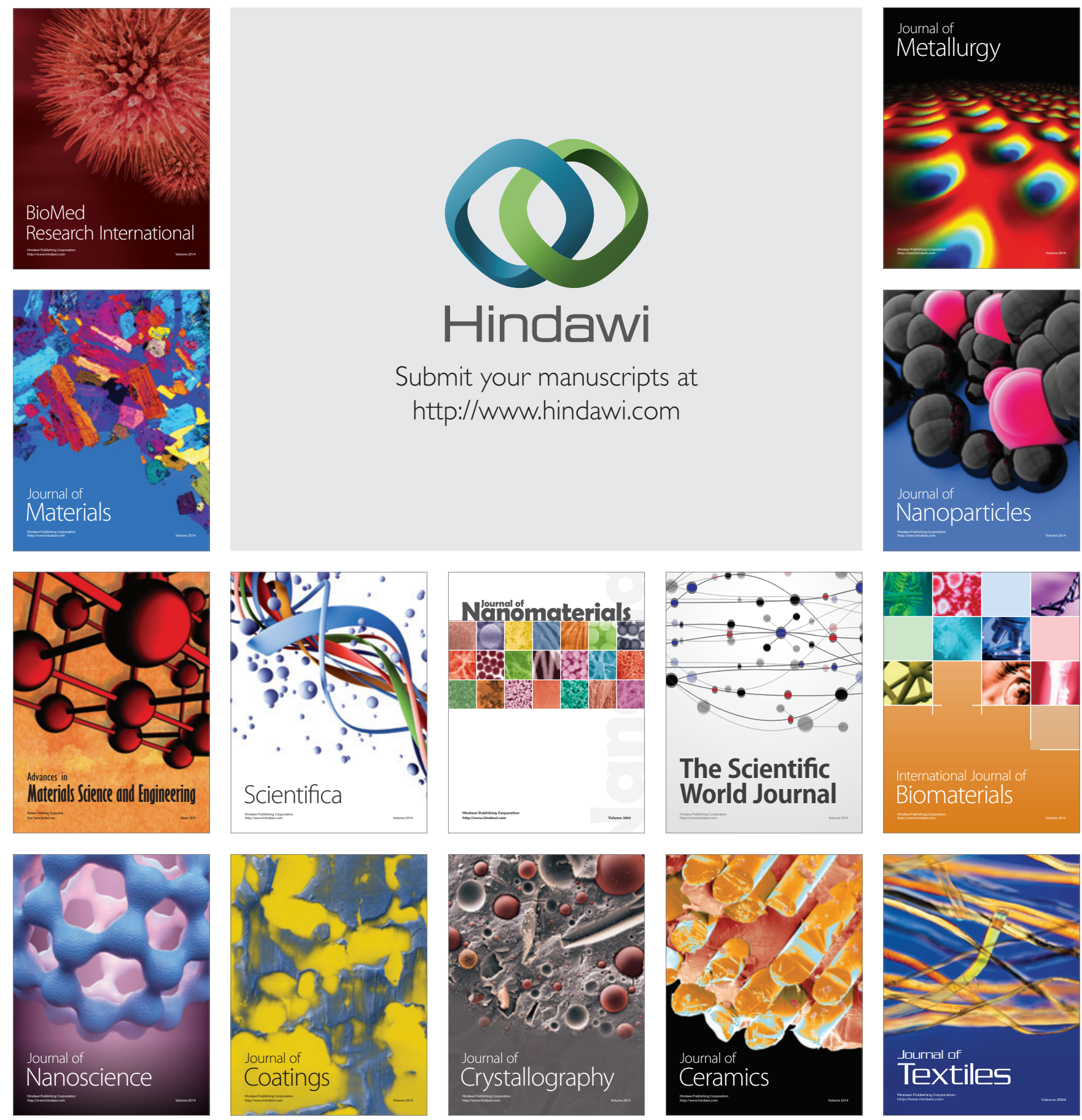